\title{
Sosialisasi dan implementasi program smart village di Kecamatan Benai, Kabupaten Kuantan Singingi
}

\author{
Okta Karneli*, Ruzikna, Kasmirudin, Frini Karina Andini
}

Universitas Riau

*oktakarneli@yahoo.com

\begin{abstract}
Abstrak. Pembangunan pedesaan saat ini mengalami perubahan yang signifikan baik konsep maupun prosesnya. Konsep pembangunan desa tidak lagi sebatas pada sector agraris dan infrastruktur dasar, namun sudah mengarah pada pengembangan Teknologi Informasi dan Komunikasi (TIK). Seiringi dengan itu, kecamatan benai kabupaten kuantan singingi telah mencanangkan penggunaan fasilitas internet sejak 2018 lalu melalui program desa digital. Kondisi ini menjadi peluang bagi masyarakat Benai, Kecamatan Kuantan Singingi untuk dapat menggunakan internet secara cerdas dan dapat mengembangkan potensi desa serta UMKM yang dimiliki masyarakat untuk meningkatkan perekonomian dan kesejahteraan masyarakat. Hal inilah yang menjadi fokus dalam program pembinaan yang dilakukan. Kegiatan pembinaan ini dilakukan dengan metode adalah penyampaian materi atas pentingnya penggunaan internet cerdas dalam meningkatkan kesejahteraan perekonomian, mendiskusikan potensi yang dimiliki, mendiskusikan masalah serta solusi yang diperoleh dalam menghadapi permasalahan yang ada. Serta, mengadakan simulasi penggunaan internet cerdas. Program pembinaan ini menghasilkan penyelesaian permasalahan keterbatasan kemampuan serta peningkatan kemampuan masyarakat dalam menggunakan internet cerdas, mengembangkan UMKM yang dimiliki oleh masyarakat agar dapat berkembang secara berkelanjutan sehingga dapat meningkatkan kesejahteraan masyarakat.
\end{abstract}

Kata kunci: smart village; desa; ekonomi; kesejahteraan; teknologi informasi dan komunikasi

\begin{abstract}
Village development is currently experiencing significant has change in concepts and processing. Villlage development concept not just in agraris sector and base infrastructure, but has been pointing in information technology and communication development. Since 2018, internet network has come to this district, and become an oppourtunity for the community to use the smart internet and develop village potential and community business to increase the economics and prosperity. These are the focus of this coaching program. The method of this coacing program are description concept to use smart internet to increase the prosperity and economics, discuss the potential, problem and solution their problem and simulation for the practice. The result of this program are solve their problem about the ability and increase the community ability to use smart internet and their can develop their business to be more suistanable and can increase the prosperity.
\end{abstract}

Keywords: smart village; village; economic; prosperity; information technology and communication

To cite this article: Karneli, O., Ruzikna, Kasmirudin, \& F. K. Andini. 2019. Sosialisasi dan implementasi program smart village di Kecamatan Benai, Kabupaten Kuantan Singingi. Unri Conference Series: Community Engagement 1: 139-143. https://doi.org/10.31258/unricsce.1.139-143

(C) 2019 Authors

Peer-review under responsibility of the organizing committee of Seminar Nasional Pemberdayaan Masyarakat 2019 


\section{PENDAHULUAN}

Pembangunan pedesaan saat ini mengalami perubahan yang dirasakan signifikan, baik dalam konsep maupun prosesnya. Konsep pembangunan desa tidak lagi sebatas pada sector agraris dan infrastruktur dasar, namun sudah mengarah pada pengembangan Teknologi Informasi dan Komunikasi (TIK). Proses pembangunan desa saat ini sudah mulai menjajaki sistem otoritas dari masyarakat yang semakin berdaya dan kreatif dalam berinovasi. Hal ini didukung dengan adanya peran akademisi serta BUMN ataupun perusahaan swasta yang sudah memiliki concern terhadap pembangunan desa, walaupun masih memiliki ketergantungan terhadap peran pemerintah.

Menurut Supritna (2000), pembangunan desa merupakan pembangunan yang dilaksanakan secara menyeluruh dan terpadu dengan kewajiban yang serasi antara pemerintah dan masyarakat, dimana pemerintah wajib memberikan bimbingan, pengarahan, bantuan dan fasilitas yang diperlukan. Sedangkan masyarakat memberikan partisipasinya dalam bentuk swakarya dan swadaya gotong royong masyarakat pada setiap pemabngunan yang diinginkan untuk meningkatkan pendapatan dan kesejahteraan masyarakat di pedesaan.

Berangkat dari visi pemerintah saat ini yang ingin membangun dari pinggiran, diartikan bahwa fokus pembangunan saat ini adalah dari level terendah, yaitu desa atau kampung. Berdasarkan data BPS Tahun 2015 jumlah penduduk pedesaan mencapai $46,7 \%$ yang relatif menunjukkan cukup besar potensi di desa untuk menekan dan mengambil peran turut serta mengatasi problematika urbanisasi. Disamping itu, angka ini menunjukkan bahwa dominannya penduduk Indonesia hidup di perkotaan menjadikan desa kurang mendapatkan fokus pengembangan yang optimal serta masih bertindak secara tradisional dalam mengelolanya.

Pelaksanaan pembangunan pedesaan di era digital ini memerlukan sistem komunikasi konvergen yang melibatkan komunikasi interpersonal, media masa, dan media hibrida. Tujuannya agar banyak pihak dari berbagai generasi dapat terlibat dan berpartisipasi untuk mempercepat tujuan pembangunan. Sebab proses tidak bisa mengabaikan keterlibatan dari elemen masyarakat (Badri, 2016).

Untuk itu diperlukan sebuah model pengembangan desa yang lebih optimal, innovative, dan cerdas (smart) dengan menggunakan asset atau sumber daya yang lebih terorganisir dengan baik dan memberikan kemajuan bagi desa. Solusi cerdas ini diterapkan melalui konsep desa cerdas atau smart village, yang merupakan salah satu upaya yang dilakukan oleh pemerintah dan swasta, serta akademisi dan elemen masyarakat lainnya untuk membangun dan mengembangkan sebuah desa dengan konsep desa cerdas dengan menjadikan desa yang lebih baik dari aspek ekonomi, sosial, budaya, politik dan sebagainya.

Salah satu kecamatan yang sudah mencanangkan program smart village adalah kecamatan Benai Kabupaten Kuantan Singingi. Kabupaten yang memiliki potensi sumber daya alam yang berlimpah, baik dari segi potensi alam maupun potensi pariwisatanya ini memiliki luas wilayah $7.656,03 \mathrm{~km}^{2}$, dengan jumlah penduduk 317.935 jiwa, dan 15 kecamatan, yaitu Kecamatan Benai Cerenti, Gunung Toar, Inuman, Hulu Kuantan, Kuantan Hilir, Kuantan Hilir Seberang, Kuantan Mudik, Kuantan Tengah, Logas Tanah Datar, Pangean, Pucuk Rantau, Sentajo Raya, Singingi dan Singingi Hilir (www.bps.go.id).

Program smart village sudah mulai dilaksanakan Kecamatan Benai sejak tahun 2018 dengan tujuan untuk memberikan kemudahan pelayanan yang lebih baik pada masyarakat desa. Kecamatan yang terdiri dari 16 desa/ kelurahan dengan luas 124,66 $\mathrm{km}^{2}$ dan jumlah penduduk sebesar 16.194 jiwa, pada umumnya mempunyai mata pencaharian dibidang pertanian, dengan jenis komoditas karet, kakao, kelapa sawit, dan aneka tanaman lainnya. Optimalisasi program smat village akan berdampak terhadap peningkatan hasil perkebunan, pertanian dan pengembangan potensi yang dimiliki oleh Kecamatan Benai. Menerapkan program atau konsep smat village dalam membangun desa tidak hanya focus pada kecanggihan teknologi, namun yang lebih utama adalah bagaimana konsep ini dapat mengubah keadaan masyarakatnya menjadi lebih baik. Pemahaman tentang konsep smat village ini diharapkan dapat menumbuhkan kesadaran masyarakat tentang pentingnya melakukan inovasi dalam berusaha sehingga tercipta jiwa-jiwa kewirausahaan. Selain itu juga diharapkan dapat memberikan kualitas pelayanan yang lebih baik kepada masyarakat

Kegiatan pengabdian pada masyarakat ini bertujuan untuk mensosialisasikan dan mengimplementasikan tentang program Smart Village serta manfaatnya dalam meningkatkan potensi desa pada masyarakat. Selain itu juga bertujuan dapat menerapkan program Sedangkan secara khusus bertujuan untuk meningkatkan kesejahteraan masyarakat pelaku usaha kecil menengah melalui peningkatakan pemahaman tentang pentingnya berinovasi. Salah satunya adalah dengan pemanfaatan teknologi informasi dalam meningkatkan penjualan dan produksi hasil pertanian dan perkebunan. 


\section{METODE}

Metode yang digunakan dalam pelaksanaan kegiatan pengabdian pada masyarakat ini terdiri atas 3 tahapan, yaitu:

\section{Tahap Persiapan}

Pada tahap persiapan ini dilakukan survey lokasi dan diskusi dengan perangkat kecamatan tentang permasalahan yang ada. Dilanjutkan dengan analisis dan diskusi tentang program atau kegiatan yang akan dilaksanakan sesrta penentuan waktu, lokasi, sasaran serta peserta pelatihan.

\section{Tahap Pelaksanaan}

Tahap ini merupakan tahapan dimana kegiatan pengabdian dilaksanakan di lokasi pengabdian sebanyak 5 sesi yaitu: Sesi pertama adalah pre test tentang pemahaman peserta terhadap program smart villag. Sesi kedua, penyampai materi mengenai arti pentingnya program serta manfaat bagi masyarakat. Sesi ketiga, diskusi mengenai potensi yang dimiliki serta masalah yang dihadapi dan solusi dari permasalahan tersebut. Sesi keempat pelatihan dan praktek menggunakan salah satu aplikasi dalam melakukan penjualan hasil usaha. Sesi kelima, diskusi dan posttest dan diakhiri dengan penyerahan modem portable untuk mendukung program smart village untuk masyarakat desa yang diterima oleh sekretaris camat.

\section{Tahap Evaluasi dan Monitoring}

Tahap evaluasi ini merupakan tahapan tinjauan ulang atas kegiatan pengabdian yang telah dilakukan kepada masyarakat. Pada tahapan ini akan dilihat umpan balik kepada masyarakat serta efektifitas dan efisiensi kegiatan dan pelaksanaan setelah kegiatan pengabdian dilakukan.

\section{PEMBAHASAN}

Dalam menggambarkan potensi masyarakat, pengabdian ini dilihat dari peserta yang mewakili 15 desa dan 1 Kelurahan yang ada di Kecamatan Benai dengan jumlah masing-masing desa diwakili oleh 2 orang dengan karakteristik peserta mengetahui tentang internet dan memiliki usaha baik UKM, maupun perkebunan atau hasil pertanian. Peserta yang berjumlah 32 orang dalam pengabdian ini didominasi oleh perempuan yang memiliki usaha.

Berdasarkan hasil kegiatan pengabdian ini, diperoleh informasi dari post test dan test setelah adanya sosialisasi, bahwa 84\% (27 orang) belum atau tidak mengetahui adanya desa pintar (smart village) serta manfaatnya. Sedangkan sisanya sebanyak $16 \%$ (5 orang) sudah mengetahui namun hanya sekedar mendengar dan mendapatkan informasi dar anggota keluarga. Masyarakat memahami bahwa fasilitas internet yang disediakan desa hanya sebagai fasilitas yang cukup menunjang kehidupan sehari - hari untuk bersosialisasi di media sosial saja seperti hanya untuk fasilitas chat bersama keluarga di kota atau dikampung. Setelah diadakan sosialisasi dan penyampaian materi tentang apa dan manfaat dari adanya desa pintar, didapat informasi bahwa hampir semua peserta yaitu 94\% (30 orang) sudah mengetahui dan memahami tentang desa pintar dan menganggap program desa pintar sangat berguna bagi mereka. Sedangkan sisanya yaitu 6\% (2 orang) masih belum dapat memahami dengan baik disebabkan keterbatasan dalam pengetahuan.

Masalah yang ada didalam masyarakat desa di Kecamatan Benai ini adalah kurangnya pengetahuan mengenai kegunaan internet atau media digital, ketidaktahuan masyarakat bahwa media digital memiliki peran penting dalam menunjang kehidupan sosial dan ekonomi, dapat mengembangkan usaha yang dimiliki, pelayanan publik yang memudahkan maasyarakat, meningkatkan pengetahuan masyarakat luas mengenai potensi yang dimiliki oleh desa-desa di Kecamatan Benai dan sebagainya.

Namun, masalah ini tentunya tidak hanya sebatas kurangnya sosialisasi atau pengetahuan masyarakat mengenai internet atau desa pintar, namun juga sangat berkaitan dengan kemampuan yang dimiliki masyarakat untuk mengoperasionalkan smartphone yang dimiliki, dan sedikitnya sumber daya manusia yang masih berusia produktif yang memiliki jiwa kreatif. Berdasarkan post test yang disebarkan kepada masyarakat, hal ini merupakan hal krusial yang menjadi masalah dalam pengembangan desa digital atau desa pintar. 


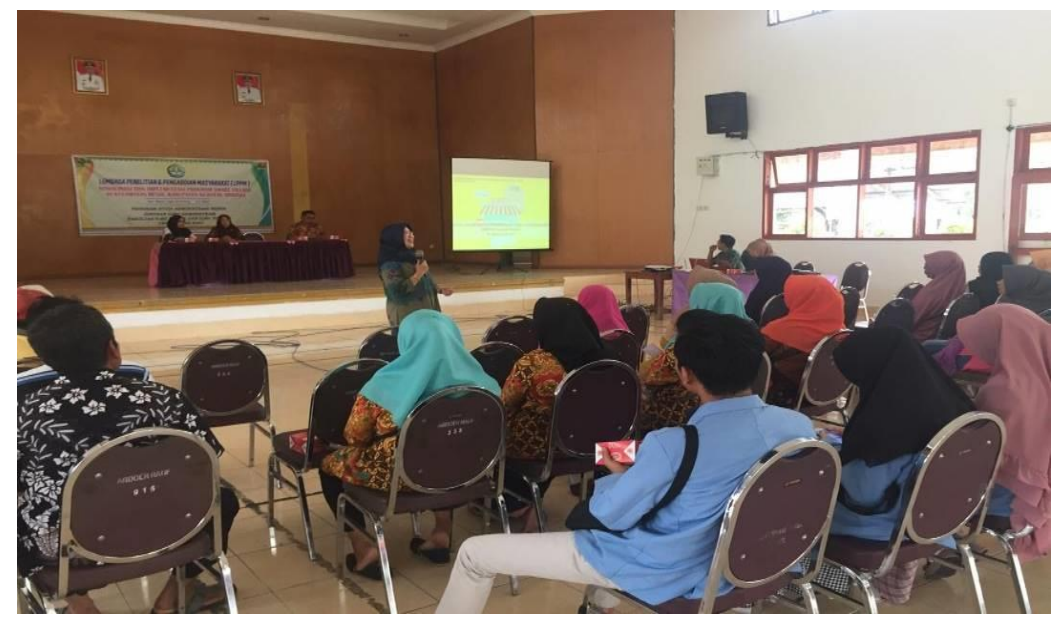

Gambar 1. Penyampai materi oleh salah seorang tim pengabdian

Dalam hal kendala bagi masyarakat adalah tidak semua desa di Kecamatan Benai sudah memiliki jaringan internet yang bagus, sejauh ini hal yang dirasakan oleh masyarakat adalah seringnya jaringan tersebut bermasalah sehingga sulit untuk mengeksplore dunia maya tersebut.

Minat dari para peserta mengikuti kegiatan pengabdian ini cukup tinggi, karena mereka meyadari bahwa sangat membutuhkan informasi dan pengetahuan mengenai desa digital agar dapat lebih mengembangkan usaha dan potensi yang dimiliki desa. Hal ini juga disebabkan karena beberapa kendala yang diharpi oleh masyarakat diatas adalah tidak adanya sosisalisasi yang datang ke masyarakat mengenai manfaat, kegunaan serta dampak dari adanya fasilitas internet yang sudah ada, sehingga dengan adanya kegiatan ini masyarakat menjadi lebih tau dan dapat menerapkan konsep desa digital atau desa pintar di masing - masing desa di Kecamatan Benai, Kabupaten Kuantan Singingi.

Berdasarkan permasalahan, kendala yang sudah dijabarkan diatas, bahwa kegiatan pengabdian ini memiliki kesesuaian dengan masalah yang dihadapi masyarakat, yakni mensosialisasikan serta mengimplementasikan konsep desa pintar pada masyarakat di Kecamatan Benai. Maka solusi yang disajikan dalam pengabdian masyarakat agar dapat memahami dan menerapkan desa digital atau desa pintar di Kecamatan ini adalah:

1. Memberikan pengetahuan mengenai konsep desa pintar atau desa digital, berupa manfaat, kegunaan, dampak, dan program desa pintar yang dapat diaplikasikan oleh masyarakat di Kecamatan Benai.

2. Memberikan bantuan fasilitas berupa modem agar masyarakat yang masih terkendala jaringan internet di desanya dapat tetap mengakses dunia digital untuk dapat mengembangkan usaha yang dimilikinya.

3. Memberikan arahan kepada masyarakat bahwa salah satu aspek dalam desa pintar adalah masyarakatnya yang pintar, kreatif, inovatif dan mau belajar dalam menggunakan media digital. Seperti mengembangkan usaha dengan menggunakan media digital dalam hal pemasaran produk dan juga mengekspose mengenai potensi desa ke dunia digital.

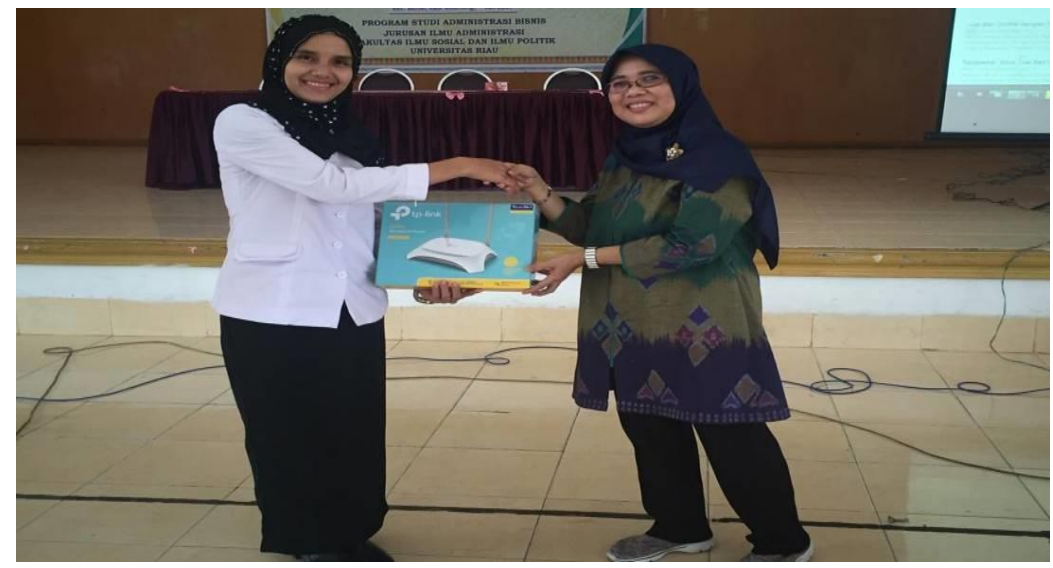

Gambar 2. Penyerahan modem portable yang diterima oleh sekretaris camat Benai 


\section{KESIMPULAN}

Berdasarkan kegiatan pengabdian kepada masyarakat dengan judul "Sosialisasi dan Implementasi konsep Smart Village di Kecamatan Benai, Kabupaten Kuantan Singingi" yang telah dilaksankaan maka diperoleh kesimpulan bahwa pengetahuan masyarakat mengenai desa digital atau desa pintar masih minim, karena selama ini masyarakat hanya mengetahui keberadaa internet ada, namun tidak dapat menggunakannya secara produktif. Dengan telah dilaksanakannya kegiatan pengabdian ini, masyarakat mengetahui bahwa keberadaan internet memiliki peran yang sangat penting dalam perekonomian masyarakat dan dalam menjadikan desa desa di Kecamatan Benai menjadi desa maju dan berkembang dengan memanfaatkan fasilitas internet dan menjadikannya desa pintar.

Adapun saran dari adanya kegiatan pengabdian ini adalah perlu adanya pelatihan dan pendampingan secara berkala yang dilakukan oleh akademisi yang bekerja sama dengan pemerintah untuk mendampingi masyarakat dalam menggunakan media internet untuk mengembangkan usaha, meningkatkan perekonomian, menjadikan desa-desa di Kecamatan Benai menjadi desa yang maju dengan mengusung konsep Desa Digital atau Desa Pintar. Saran lainnya adalah pemerintah dalam hal pelayanan publik juga perlu melalukan terobosan baru yang inovatif untuk memancing daya kreatifitas masyarakat dalam mengusung konsep desa pintar untuk Kecamatan Benai.

\section{DAFTAR PUSTAKA}

Adisasmita, R. 2006. Pembangunan Pedesaan dan Perkotaan. Yogyakarta: Graha Ilmu.

Anonym. 2019. Smart Village. https://www.kompasiana.com/ilmanaili/5be1c35043322f36bc21dd97 Diakses pada 14 Agustus 2019.

Badri, M. 2016. Sistem Komunikasi Pembangunan Pedesaan Berbasis Teknologi Informasi Dan Komunikasi.

Bourne, L. S. 1971. Internal Structure Of The City. New York: Oxfrord University Prees.

Department for Business, Innovation and Skills. 2013. Smart Cities: Background Paper. www.nationalarchives.gov.uk/doc/open-government-licence

Kartasasmita, G. 2001. Pembangunan Untuk Rakyat: Memadukan Pertumbuhan dan Pemerataan. Jakarta: Pustaka CIDESINDO.

Permana, A. Y. 2011. Penerapan Konsep Perancangan Smart Village sebagai Local Genius Arsitektur Nusantara. Jurnal Arsitektur Komposisi 9(1).

Razak, N. A., J. A. Malik, and M. Saeed. 2013. A Development of Smart Village Implementation Plan for Agriculture: A Pioneer Project in Malaysia. Proceedings of the 4th International Conference on Computing and Informatics, ICOCI 2013 28-30 August, 2013 Sarawak, Malaysia. Universiti Utara Malaysia.

Tjahja, S. 2000. Strategi Pembangunan dan Kemiskinan. Jakarta: Rineke Cipta.

Viswanadham, N. 2013. Smart Village and Smart City. Ecosystem Aware Global Supply Chain Management. World Science. 